\title{
Virulence Structure Within Populations of Pseudoperonospora cubensis in the United States
}

\author{
Anna Thomas, Ignazio Carbone, Aleš Lebeda, and Peter S. Ojiambo
}

First, second, and fourth authors: Center for Integrated Fungal Research, Department of Entomology and Plant Pathology, North Carolina State University, Raleigh 27695; and third author: Department of Botany, Palacký University, 78371 Olomouc, Czech Republic. Accepted for publication 5 February 2017.

\begin{abstract}
Cucurbit downy mildew (CDM), caused by the obligate oomycete Pseudoperonospora cubensis, has resurged around the world during the past three decades. A new pathotype or genetic recombinant of $P$. cubensis have been suggested as possible reasons for the resurgence of CDM in the United States in 2004. In total, 22 isolates collected between 2004 and 2014, mainly in the eastern United States, were tested for their compatibility with a set of 15 cucurbit host types. The virulence structure within these isolates was evaluated on a set of 12 differential genotypes from eight genera. All isolates were highly compatible with the susceptible cultivar of Cucumis sativus, whereas the least compatibility was observed with Luffa cylindrica and Momordica charantia. Based on the compatibility with the differential host set, five pathotypes $(1,3,4,5$, and 6$)$ were identified among the 22 isolates examined. Pathotypes 1 and 3 had not been previously described in the United States and isolates of these two new pathotypes were also compatible with 'Poinsett 76', a cultivar of $C$. sativus known to be resistant to $\mathrm{CDM}$ prior to 2004 . Virulence within the pathogen population was

expressed based on virulence factors, virulence phenotypes, and virulence complexity. The number of virulence factors ranged from two to eight, indicating a complex virulence structure, with $77 \%$ of the isolates having five to eight virulence factors. Thirteen virulence phenotypes were identified; the mean number of virulence factors per isolate and mean number of virulence factors per virulence phenotype was 5.05 and 5.23, respectively, indicating that complex isolates and phenotypes contributed equally to the complex virulence structure of $P$. cubensis. Gleason and Shannon indices of diversity were 3.88 and 2.32, respectively, indicating a diverse virulence structure of $P$. cubensis within the United States population. The diverse virulence and high virulence complexity within the pathogen population indicate that host resistance alone in available cucurbit cultivars will not be effective to control CDM. An integrated approach involving a combination of fungicide application and introduction of cultivars with new resistance genes will be required for effective management of CDM.
\end{abstract}

Cucurbitaceae is a fairly large family and includes more than 118 genera and 825 species, with members distributed widely throughout the tropics and warm temperate regions of the world (Lebeda et al. 2007). In the United States, cucurbits are an important group of vegetable crops and account for approximately $10 \%$ of the total value of vegetables produced nationally (Anonymous 2016). The most widely grown cucurbits include cucumber, cantaloupe, pumpkin, squash, and watermelon. In 2014, cucurbits were produced on approximately 390,000 acres concentrated mainly in the eastern half of the United States and in Arizona, California, and Texas and were valued at $\$ 1.5$ billion (Anonymous 2016). Florida, Georgia, and North Carolina are among the major producers of cucumber, squash, and melon, accounting for more than $32 \%$ of the total value of the crop produced in the United States (Anonymous 2016).

Cucurbit downy mildew (CDM), caused by the obligate oomycete Pseudoperonospora cubensis, is one of the most economically important limiting factors in cucurbit production worldwide (Lebeda and Cohen 2011; Ojiambo et al. 2015). This is particularly the case because the resurgence of CDM in many parts of the world during the last decade has resulted in severe epidemics and crop losses (Cohen et al. 2015; Holmes et al. 2015). In the United States, the disease was only of minor concern on cucumber prior to 2004 and required very little application of fungicides due to resistant cultivars deployed in 1960s using the resistance source Plant Introduction (PI) 197087 (Barnes and Epps 1954). However, this long-standing resistance that was effective for approximately 40 years was overcome, resulting in a resurgence of the disease in the United States in 2004 (Holmes et al.

Corresponding author: P. S. Ojiambo; E-mail address: peter_ojiambo@ncsu.edu

(C) 2017 The American Phytopathological Society
2006). Resurgence of CDM was also reported in Israel in 2002 (Cohen et al. 2003) and in Europe in 1985 and 2009 (Lebeda et al. 2011). In the United States, resurgence of CDM resulted in severe epidemics in the eastern part of the country in 2004 and 2005, resulting in significant crop losses (Holmes et al. 2006). In the United States, CDM now occurs annually, posing a significant threat to cucurbit production (Holmes et al. 2015).

Resurgence of CDM has dramatically affected production of cucurbits and deployment of disease management options worldwide (Holmes et al. 2015). Thus, considerable efforts have been initiated to determine and understand possible causes for the resurgence of CDM in Europe (Kitner et al. 2015; Lebeda et al. 2013), Israel (Cohen et al. 2015), and the United States (Holmes et al. 2015; Ojiambo et al. $2015)$ to devise effective disease management strategies. Anthropogenic introduction of new pathotypes of $P$. cubensis, possibly from Asia, has been suggested as a plausible explanation for the resurgence of CDM around the world (Runge et al. 2011). In P. cubensis, pathotypes are physiological forms of the pathogen that differ in host specificity on the level of genus, species, or subspecies of various cucurbits (Lebeda and Widrlechner 2003). As in other oomycetes, the interaction between P. cubensis and cucurbits is discontinuous and displays a compatible or incompatible reaction pattern. This compatible or incompatible reaction with a set of differential host species is the basis for classifying pathotypes of $P$. cubensis. Thomas et al. (1987) first identified pathotypes of $P$. cubensis based on a differential set composed of Cucumis sativus, C. melo var. reticulatus, $C$. melo var. conomon, C. melo var. acidullus, Citrullus lanatus and Cucurbita pepo. Isolates capable of infecting Cucumis sativus and C. melo var. reticulatus were identified as pathotype 1, while those capable of infecting C. melo var. conomon in addition to the former hosts were considered to be pathotype 2. Isolates capable of infecting all the Cucumis spp. were considered to be pathotype 3 . 
All isolates capable of infecting Citrullus lanatus in addition to the Cucumis spp. were identified as pathotype 4 and all those that were capable of infecting Cucurbita spp. in addition to Cucumis spp. and C. lanatus were considered to be pathotype 5. Isolates from Japan belonged to pathotype 1,2 , or 3 , whereas those from the United States belonged to pathotype 4 or 5 (Thomas et al. 1987). The host differential set proposed by Thomas et al. (1987) to designate pathotypes was composed of 6 differentials from three genera and it was later expanded to 12 genotypically well-defined differentials from six genera that also include Benincasa, Luffa, and Lagenaria (Lebeda and Widrlechner 2003). Recently, the latter host differential set has been expanded to 15 differentials to include hosts from two additional genera, Momordica and Trichosanthes (Cohen et al. 2015).

New pathotypes and shifts in virulence within the population of $P$. cubensis have been associated with the resurgence of CDM around the world. For example, Lebeda et al. (2013) reported new pathotypes and an increase in the host range of $P$. cubensis following the resurgence of CDM in Czech Republic in 2009. A new pathotype (pathotype 6) that did not infect watermelon but caused severe disease outbreaks on pumpkin and summer squash appeared in Israel in 2002 (Cohen et al. 2003). Similarly, pathotype 5 that was aggressive on squash appeared in Italy in 2002 (Cappelli et al. 2003). Some surveys (Cohen et al. 2015) have indicated the presence of pathotypes 7, 8, 9, and 10 in China, Vietnam, Russia, and India, respectively. Systematic studies on the virulence structure within the population of $P$. cubensis are still lacking in the United States. Earlier work by Thomas et al. (1987), which included only two isolates, indicated the presence of only pathotypes 4 and 5 in the United States. Colucci (2008) later conducted a more comprehensive study on the host range of $P$. cubensis following the 2004 resurgence of CDM and concluded that the pathogen population was very diverse after disease resurgence in the United States. However, no pathotypes were identified, nor was the level of virulence diversity quantified in that study. In addition, a link between changes in virulence of $P$. cubensis and the resurgence of CDM in the United States has not been established.

Knowledge of prevailing pathotypes is essential for deployment of host resistance for effective disease management. In the United States, Cespedes-Sanchez et al. (2015) recently reported no differences in the dominant pathotypes of $P$. cubensis in Michigan between 2010 and 2011. However, no specific pathotypes of $P$. cubensis were identified in that study to determine whether they were different from those reported earlier by Thomas et al. (1987). Documentation of prevailing pathotypes is a useful reference for the study by
Thomas et al. (1987) when determining whether pathotypes other than pathotypes 4 and 5 are present in the United States. In a recent study (Thomas et al. 2017) based on a limited sample size, isolates characterized as pathotypes 1 and 3 were all of the A1 mating type, whereas those characterized as pathotypes 4 and 5 were of the A2 mating type. It would be interesting to determine whether this association between pathotype and mating type holds using a robust set of isolates. Given that host range studies are laborious and time consuming, genotypic markers associated with mating types (Lebeda et al. 2014) could be used to rapidly determine and narrow down potential pathotypes and, hence, the host range of $P$. cubensis within a given field. To further elucidate the pathotype and mating type structure of $P$. cubensis, this study focused on the following specific objectives: (i) establish the current host range of $P$. cubensis collected from various cucurbit hosts, (ii) determine the prevailing pathotypes of $P$. cubensis within the pathogen population, (iii) establish virulence and virulence diversity within the $P$. cubensis population, and (iv) characterize the prevalence and distribution of the mating types of $P$. cubensis within the prevailing pathotypes of $P$. cubensis in the United States.

\section{MATERIALS AND METHODS}

Isolate collection and maintenance. In total, 22 isolates of $P$. cubensis generated from single lesions were used in this study. The isolates were obtained from different cucurbit host types that included cucumber, cantaloupe, watermelon, pumpkin, butternut squash, and acorn squash, primarily from the eastern United States (Table 1). All isolates were collected from 2005 to 2013 except Pc1982, which was originally isolated from cantaloupe leaves collected in South Carolina in 1982. Isolate Pc1982 was previously stored at $-80^{\circ} \mathrm{C}$ and maintained by periodic reinoculation on detached cantaloupe leaves under controlled conditions.

Single-lesion isolates were obtained from field samples of infected leaves of cucurbits collected by cooperators in the CDM ipmPIPE disease monitoring network (Ojiambo et al. 2011) and shipped to the Plant Pathology Laboratory at North Carolina State University in Raleigh. Leaves of infected samples were carefully examined and isolates from leaves with discrete lesions were subsequently maintained on their respective hosts in the laboratory as single-lesion isolates. Leaf samples without discrete single lesions were further processed to generate single-lesion isolates using host types from which isolates were originally obtained.

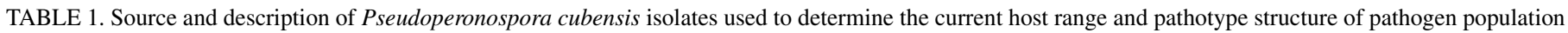
in the eastern United States

\begin{tabular}{|c|c|c|c|c|c|}
\hline Isolate & Host of origin & Host species & Year & State & County \\
\hline 08F1 & Acorn squash & Cucurbita реро & 2008 & Georgia & Tift \\
\hline $2013 F 2$ & Acorn squash & C. реро & 2013 & South Carolina & Charleston \\
\hline 2013F11 & Acorn squash & C. реро & 2013 & New York & Suffolk \\
\hline D3 & Butternut squash & C. moschata & 2012 & South Carolina & Charleston \\
\hline 2013D2 & Butternut squash & C. moschata & 2013 & Florida & Hillsborough \\
\hline 2013D4 & Butternut squash & C. moschata & 2013 & North Carolina & Johnston \\
\hline 2013D6 & Butternut squash & C. moschata & 2013 & Alabama & Escambia \\
\hline Pc1982 & Cantaloupe & Cucumis melo & 1982 & South Carolina & Charleston \\
\hline 2013B17 & Cantaloupe & C. melo & 2013 & New York & Ontario \\
\hline $05 \mathrm{~A} 1$ & Cucumber & C. sativus & 2005 & Michigan & Oceana \\
\hline 08A1 & Cucumber & C. sativus & 2008 & California & Salinas \\
\hline A11 & Cucumber & C. sativus & 2012 & North Carolina & Johnston \\
\hline 2013A3 & Cucumber & C. sativus & 2013 & Georgia & Worth \\
\hline 2013A10 & Cucumber & C. sativus & 2013 & South Carolina & Charleston \\
\hline 2013A15 & Cucumber & C. sativus & 2013 & Alabama & Macon \\
\hline 2013A18 & Cucumber & C. sativus & 2013 & New Jersey & Salem \\
\hline 2013A19 & Cucumber & C. sativus & 2013 & Ohio & Sandusky \\
\hline 2013A20 & Cucumber & C. sativus & 2013 & Ohio & Medina \\
\hline $2013 C 3$ & Giant pumpkin & Cucurbita maxima & 2013 & North Carolina & Johnston \\
\hline $08 \mathrm{C} 1$ & Pumpkin & C. maxima & 2008 & New York & Suffolk \\
\hline 08E1 & Watermelon & Citrullus lanatus & 2008 & Texas & Bryan \\
\hline 2013E1 & Watermelon & C. lanatus & 2013 & Florida & Collier \\
\hline
\end{tabular}


Sporangia from such lesions were washed off infected leaves using a Preval sprayer (Complete Unit 267; Precision Valve Corporation, Yonkers, NY) and the suspension was used to inoculate whole plants at a concentration of approximately $1 \times 10^{4}$ sporangia $/ \mathrm{ml}$. Inoculated plants were bagged with polythene bags and incubated in a growth chamber at $18^{\circ} \mathrm{C}$ with no light for $24 \mathrm{~h}$. After $24 \mathrm{~h}$, plants were unbagged and incubated at 21 and $18^{\circ} \mathrm{C}$ (day and night, respectively) for disease development, with a photoperiod of $12 \mathrm{~h}$. Plants were examined daily for symptoms and, when discrete single lesions were visible, plants were bagged again and kept under dark conditions for $24 \mathrm{~h}$ to stimulate sporangia production. An individual lesion was subsequently cut from a leaf and collected sporangia were used to inoculate the original host to multiply sporangia of each isolate. To propagate isolates, first or second leaves were placed on sterile, moist paper towels in clear acrylic boxes. Abaxial sides of the leaves were then inoculated with approximately $2 \times 10^{4}$ sporangia/ml and incubated in a growth chamber at 21 and $19^{\circ} \mathrm{C}$ (day and night, respectively) and a photoperiod of $12 \mathrm{~h}$. All isolates were maintained in the laboratory by propagating them on their respective hosts using the detached-leaf assay until they were ready for use in subsequent experiments.

Host range and pathotypes. Isolates collected in this study were used to determine the host range of $P$. cubensis based on compatibility reaction with cultivated and wild cucurbit hosts belonging to eight genera: Cucumis (Cucumis sativus, C. melo var. reticulatus, and C. melo var. conomon), Citrullus (Citrullus lanatus), Cucurbita (Cucurbita moschata, C. pepo, and C. maxima), Luffa (Luffa cylindrica), Lagenaria (Lagenaria siceraria), Trichosanthes (Trichosanthes cucumerina), Benincasa (Benincasa hispida), and Momordica (Momordica charantia) (Table 2). The differential Cucumis melo var. acidulus used by Thomas et al. (1987) was not included in this study due to lack of seed. To promote germination, seed of C. melo var. reticulatus, C. melo var. conomon, Citrullus lanatus, Luffa cylindrica, and Lagenaria siceraria were pregerminated on moist filter papers in glass Petri plates in an incubator at $30^{\circ} \mathrm{C}$ for 5 to 6 days. Seed of T. cucumerina and B. hispida were first soaked in warm water for $24 \mathrm{~h}$, whereas seed of $M$. charantia were soaked in water at room temperature for $24 \mathrm{~h}$ prior to the pregermination treatment described above. For T. cucumerina, tips of the seed area where the radicle emerges were also slightly broken off to facilitate emergence of radicles prior to the pregermination treatment. Seeds of Cucumis sativus and all pregerminated seeds were then planted in small plastic cups and placed in the greenhouse at a cycle of 26 and $22^{\circ} \mathrm{C}$ (day and night, respectively) where all plants were maintained.

Compatibility of isolates with differential hosts was determined using a detached-leaf assay. First and second primary leaves from 4 to 5-week-old plants were placed with the adaxial side on moist paper towels in clear acrylic boxes and inoculated as described above with $5 \times 10^{3}$ sporangia/ml. A negative control with water-only inoculation was included in the assay. Inoculated leaves were then incubated in a growth chamber at 21 and $18^{\circ} \mathrm{C}$ under a cycle of $12 \mathrm{~h}$ each of light and darkness and monitored for symptoms. Disease severity (DS) (percent leaf area infected) and sporulation were assessed at 5 and 7 days after inoculation, respectively. To assess sporulation, two leaf discs measuring $9 \mathrm{~mm}$ in diameter were cut from each leaf and vortexed for $20 \mathrm{~min}$ in microcentrifuge tubes containing $500 \mu \mathrm{l}$ of $50 \%$ ethanol to dislodge the sporangia (Cohen et al. 2003). Sporangial counts were then determined using a hemocytometer and expressed as sporangia per square centimeter of leaf tissue. Acrylic boxes with inoculated leaves were arranged in the growth chamber in a completely randomized design and the assay was repeated at least once.

Compatibility of $P$. cubensis with cucurbit hosts has been assessed previously based only on sporulation intensity (Cohen et al. 2003; Lebeda et al. 2012) but also using both sporulation intensity and DS (Salati et al. 2010). Here, both sporulation and DS were used to provide a comprehensive assessment of compatibility reaction as follows: (i) high compatibility $=$ sporulation rate of approximately $5 \times 10^{3}$ sporangia/ $\mathrm{cm}^{2}$ of leaf tissue and DS $\geq 50 \%$, (ii) moderate compatibility = sporulation rate of approximately $3 \times$ $10^{3}$ sporangia $/ \mathrm{cm}^{2}$ and $20 \% \leq \mathrm{DS}<50 \%$, iii) low compatibility = sporulation rate of approximately $2 \times 10^{3}$ sporangia $/ \mathrm{cm}^{2}$ leaf tissue and $5 \%<\mathrm{DS}<20 \%$, (iii) very low compatibility $=$ sparse sporulation and $1 \%<\mathrm{DS} \leq 5 \%$, and (iv) incompatible $=$ no evidence of sporulation or disease symptoms. To classify isolates into specific pathotypes, compatibility reactions were grouped into two categories as follows: (i) compatible $(+)=$ highly compatible reaction as described above and (ii) incompatible $(-)=$ moderate, low compatibility, very low compatibility, or an incompatible reaction as described above. Isolates were subsequently classified into pathotypes based on their patterns of compatible and incompatible reaction with the differential host set, composed of eight genera (Cohen et al. 2003, 2015; Lebeda and Gadasová 2002; Thomas et al. 1987).

Mating type determination. The mating type of $P$. cubensis isolates was determined as described by Cohen and Rubin (2012) by pairing of sporangia of an unknown isolate with sporangia of a tester strain (Thomas et al. 2017) with a known mating type. Here, equal proportions $(1: 1, \mathrm{vol} / \mathrm{vol})$ of sporangial suspension $\left(2 \times 10^{4}\right.$ spores/ $\mathrm{ml}$ ) of the tester and unknown isolate were mixed together and the resultant suspension was used to inoculate detached first true leaves of cantaloupe ('Ananas') or cucumber ('Straight Eight') plants. Cantaloupe and cucumber have been reported as favorable hosts for oospore production (Cohen and Rubin 2012). Plants were grown and maintained in the greenhouse as described above and repeated seeding was conducted to ensure a steady supply of the first true leaves that were used in the assay. The adaxial side of the detached leaves was placed on moist paper towels in clear acrylic boxes,

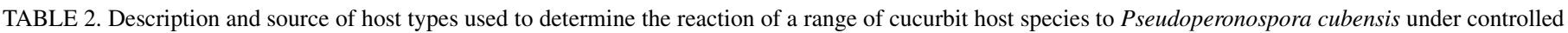
inoculation assays in the United States

\begin{tabular}{|c|c|c|c|c|}
\hline Host type & Acronym & Common name & Cultivar & Seed supplier \\
\hline Benincasa hispida & $\mathrm{BH}$ & Wax gourd & Lai Jud & Kitazawa Seed \\
\hline Citrullus lanatus & CL & Watermelon & Mickylee & Hollar Seed \\
\hline Cucumis sativus & CS1 & Cucumber & Straight Eight & Wyatt-Quarles \\
\hline C. sativus & CS2 & Cucumber & Poinsett 76 & Clifton Seed \\
\hline C. melo var. reticulatus & $\mathrm{CMr}$ & Cantaloupe & Ananas & Willhite Seed \\
\hline C. melo var. conomon & $\mathrm{CMc}$ & Pickling melon & Green Striped & Kitazawa Seed \\
\hline Cucurbita pepo subsp. ovifera & $\mathrm{CP} 1$ & Summer squash & Dixie & Seminis \\
\hline C. pepo subsp. ovifera & $\mathrm{CP} 2$ & Acorn squash & Table Queen & Wyatt-Quarles \\
\hline C. реро subsp. реро & CP3 & Pumpkin & Jack-O'Lantern & Burpee \\
\hline C. moschata & CMo & Butternut squash & Waltham & Wyatt-Quarles \\
\hline C. maxima & $\mathrm{CMa}$ & Giant pumpkin & Big Max & Wyatt-Quarles \\
\hline Lagenaria siceraria & LS & Bottle gourd & Nam Tao Yao & Kitazawa Seed \\
\hline Luffa cylindrica & $\mathrm{LC}$ & Sponge gourd & Short & Kitazawa Seed \\
\hline Momordica charantia & $\mathrm{MC}$ & Bitter gourd & Futo Spindle & Kitazawa Seed \\
\hline Trichosanthes cucumerina & $\mathrm{TC}$ & Snake gourd & Buag Ngu & Kitazawa Seed \\
\hline
\end{tabular}


while the abaxial side of the leaf was spot inoculated on at least 20 different spots with $10 \mu \mathrm{l}$ of the sporangial mixture. Inoculated leaves were then incubated in a growth chamber at $21^{\circ} \mathrm{C}$ at 50 to $60 \%$ relative humidity under a cycle of $12 \mathrm{~h}$ each of light and darkness. At 7 to 10 days postinoculation, 11-mm-diameter leaf discs were cut from infected leaves and clarified for $24 \mathrm{~h}$ in ethyl alcohol-acetic acid solution (3:1, vol/vol). Clarified leaf discs were washed three times in deionized water and then examined under a compound microscope $(\times 100$ magnification) for the presence of oospores. Unknown isolates were designated as $\mathrm{A} 1$ or $\mathrm{A} 2$ if oospores were produced in coinoculations with an A2 or A1 tester strain, respectively.

Data analysis. Sporulation intensity and DS data from experimental runs were first tested for homogeneity of variance using GLIMMIX procedure in SAS (version 9.4; SAS Institute, Cary, NC). Homogeneity tests were not significant for both sporulation $(P=0.1045)$ and DS $(P=0.4072)$ and data from experimental runs were combined for subsequent analysis. The effect of isolate and host on sporulation intensity and DS was analyzed using PROC GLIMMIX to determine the degree and extent of heterogeneity in the compatibility of $P$. cubensis with cucurbit hosts.

Virulence was quantified based on (i) number of compatible reactions for an isolate (i.e., virulence factor [v-factor]) and (ii) number of unique compatibility and incompatibility patterns for all isolates (i.e., virulence phenotype [v-phenotype]). In the first set of analysis, virulence complexity of the pathogen population was estimated as described by Andrivon (1994) based on (i) the mean number of v-factors per isolate $\left(C_{i}\right)$ and (ii) the mean number of $\mathrm{v}$-factors per v-phenotype $\left(C_{p}\right)$ as:

$$
C_{i}=\sum_{j}\left(p_{j} \cdot v_{j}\right)
$$

and

$$
C_{p}=\sum_{j}\left(v_{j}\right) / N_{p}
$$

in which $p_{j}$ is the frequency of the $j$ th v-phenotype in the population, with $j$ ranging from 1 to $N_{p} ; v_{j}$ is the number of $v$-factors in the $\mathrm{v}$-phenotype $j$ in the population; and $N_{p}$ is the number of v-phenotypes identified in the population. In the second set of analyses, diversity of v-phenotypes (Lebeda 1982) was estimated using both Gleason $\left(H_{G}\right)$ and Shannon $\left(H_{S}\right)$ indices, because the former accounts only for richness whereas the latter accounts for both evenness and richness. The indices were calculated as follows:

$$
\begin{aligned}
& H_{G}=\left[\left(N_{P}-1\right) / \ln N_{i}\right] \\
& H_{S}=-\sum_{j}\left(P_{j} \cdot \ln p_{j}\right)
\end{aligned}
$$

where $N_{i}$ is number of isolates tested, and $p_{j}$ and $N_{p}$ are as defined above. To allow for direct comparison of these diversity estimates with those reported in other studies, relative indices for the Gleason $\left(H_{G R}\right)$ and Shannon $\left(H_{S R}\right)$ were also calculated as follows:

$$
H_{G R}=\left(N_{p}-1\right) /\left(N_{i}-1\right)
$$

and

$$
H_{S R}=H_{S} / \ln N_{i}
$$

The association of pathotype with mating type among isolates collected in this study was examined using contingency tables based on the frequency of isolates within a pathotype and the number of isolates with the corresponding mating type. Differences in the distribution of A1 and A2 mating type isolates within each pathotype were examined based on Fisher's exact test using PROC FREQ in SAS.

\section{RESULTS}

Sporulation intensity and DS. Inoculation of the differential host set with $P$. cubensis isolates collected in this study resulted in different levels of sporulation intensity ranging from no sporulation to $9.54 \times 10^{4}$ sporangia/ $\mathrm{cm}^{2}$ of leaf tissue (Table 3 ). Sporulation intensity was significantly affected by isolate $(F=10.37, P<0.0001)$, differential host $(F=25.39, P<0.0001)$, and the interaction between isolate and differential host $(F=3.17, P<0.0001)$ (Table 4$)$. Sporulation intensity across all differential hosts was significantly $(P$ $<0.0001$ ) higher for isolate 2013D6, with a sporulation intensity of $2.09 \times 10^{4}$ sporangia/ $/ \mathrm{cm}^{2}$, than for all other isolates tested, except Pc1982 and 2013D2 that had an intensity of $1.66 \times 10^{4}$ and $1.85 \times 10^{4}$ sporangia/ $\mathrm{cm}^{2}$, respectively. Similarly, sporulation intensity across all isolates was significantly $(P<0.0001)$ higher on CMa that had $2.13 \times 10^{4}$ sporangia/ $/ \mathrm{cm}^{2}$ than on all other differential hosts, except CMo and CS1, that had $1.82 \times 10^{4}$ and $2.11 \times 10^{4}$ sporangia $/ \mathrm{cm}^{2}$, respectively. Inoculation of CMo with isolate 2013D6 resulted in the highest level of sporulation observed among all isolate-differential host combinations. Other isolate-differential combinations that resulted in high levels of sporulation included 2013D2 $\times$ CP3 and $2013 \mathrm{D} 6 \times \mathrm{CMa}$, with $6.66 \times 10^{4}$ and $5.81 \times 10^{4}$ sporangia $/ \mathrm{cm}^{2}$, respectively. DS also differed significantly among isolates $(F=7.22$, $P<0.0001)$, differential hosts $(F=30.65, P<0.0001)$, and the interaction between isolates and differential hosts $(F=2.57, P<$ 0.0001) (Table 4).

Compatibility reactions and pathotypes. A wide range of compatibility reactions ranging from no compatibility to highly compatible were observed when cucurbit host types were inoculated with isolates collected in this study (Table 5). For example, all isolates were highly compatible with CS1, CMr, and CMa, except 2013A20, 2013F11, and 2013D2 that had a very low compatibility with $\mathrm{CMr}$ and 2013A10 that had a very low compatibility with CMa. Similarly, all isolates had either an incompatible or a very low compatible reaction with LC, TC, and MC, except 2013A20 and Pc1982 that were highly compatible with TC (Table 5). Approximately 50\% of the isolates had a highly compatible reaction with $\mathrm{CP} 1, \mathrm{CP} 2, \mathrm{CP} 3, \mathrm{CMo}$, and $\mathrm{CS} 2$, while the remaining isolates had either an incompatible or a very low compatible reaction with these host types.

A wide range of variation in compatibility was evident when sporulation intensity data were grouped into compatible $(+)$ or incompatible $(-)$ reactions to establish pathotypes present in the study (Fig. 1). For example, the differentials CS1, CMa, CMr, and CMc were compatible with $>60 \%$ of the isolates evaluated in this study. The remaining host differentials had a compatible reaction with 18 to $40 \%$ of the isolates evaluated, except host differentials $\mathrm{LC}, \mathrm{MC}$, and TC that had a compatible reaction with $<10 \%$ of the test isolates (Fig. 1). Based on the pattern of compatibility and incompatibility reactions with the differential host set, the isolates were classified into a total of five pathotypes (Table 6). Pathotypes 1 and 3 were the most frequent, constituting 25 to $30 \%$ of the isolates evaluated, whereas pathotype 4 was the least frequent, with $<10 \%$ of the isolates tested, and included Pc1982 (Fig. 2A). None of the isolates collected in this study were classified as pathotype 2 .

v-Factors, phenotypes, complexity, and diversity. The number of $v$-factors per isolate ranged from two to eight, indicating a complex virulence, with an average of $5.05 \mathrm{v}$-factors present across all isolates examined (Table 6). The most commonly occurring $\mathrm{v}$-factor was $\mathrm{v}-5$, which was present in $41 \%$ of all the isolates tested (Table 6). Isolate Pc1982, collected in 1982, had seven v-factors. In total, 13 v-phenotypes were described in this study, with v-phenotypes P2, P3, and P9 being the most frequent and most of the remaining $\mathrm{V}$-phenotypes, including $\mathrm{P} 6$, represented by the historical isolate Pc1982, having only a single isolate (Table 6). Most v-phenotypes differed from one another by one or two v-factors.

Virulence complexity as estimated by the mean number of $v$-factors per isolate $\left(C_{\mathrm{i}}\right)$ and mean number of $\mathrm{v}$-factors per v-phenotype $\left(C_{\mathrm{p}}\right)$ was 5.05 and 5.23, respectively, for the entire pathogen population studied. Values of $C_{\mathrm{i}}$ and $C_{\mathrm{p}}$ were very similar indicating that approximately $50 \%$ of the v-phenotypes in the population were the complex v-phenotypes. Values for $H_{\mathrm{G}}$ and $H_{\mathrm{S}}$ for the population were 3.88 
and 2.32, respectively. Relative indices for the two measures of diversity, $H_{\mathrm{GR}}$ and $H_{\mathrm{SR}}$, were 0.57 and 0.75 , respectively. Given that $H_{\mathrm{GR}}$ was slightly higher than 0.5 , richness had a large contribution (compared with evenness) to the overall diversity of the $P$. cubensis population in this study.

Association of pathotype with mating type. The distribution of isolates with either A1 or A2 mating type among the five pathotypes differed significantly $\left(\chi^{2}=20.0, P<0.0001\right)$ for the isolates evaluated in the study (Fig. 2B). For example, pathotypes 1 and 3 were exclusively composed of isolates belonging to the A1 mating type. In contrast, pathotypes 4,5 , and 6 were exclusively composed of isolates of the A2 mating type (Fig. 2B).

\section{DISCUSSION}

The virulence structure of $P$. cubensis was examined in this study to determine the level and variation in the compatibility of the pathogen with cucurbit hosts, identify existing pathotypes and determine the diversity of virulence within the pathogen populations in the eastern United States. A high degree of variability in compatibility was observed between the differential host set and isolates collected from various hosts across the United States. Further, we identified a total of five pathotypes, with three pathotypes being reported for the first time in the United States. Thirteen v-phenotypes were identified, with some phenotypes and pathotypes being more frequent than others and estimates of virulence diversity and complexity being high across the entire pathogen population. This study provides the first comprehensive assessment and documentation of virulence characteristics of $P$. cubensis and serves as a useful foundation to examine the potential role of changes in its virulence structure in the 2004 resurgence of $\mathrm{CDM}$ in the United States.

The interaction of $P$. cubensis with cucurbits is very specific and results in clear patterns of compatibility or incompatibility (Thomas et al. 1987) that provide a framework to describe the population and virulence structure of the pathogen. Although $P$. cubensis is known to have a wide host range and to exhibit a high degree of pathogenic variation (Colucci 2008; Lebeda 1992; Lebeda and Cohen 2011; Lebeda et al. 2012), systematic studies on this aspect of the pathogen in the United States were still lacking. In this study, differences in compatibility of $P$. cubensis with cucurbit host types

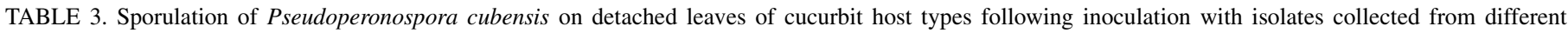
cucurbits in the United States ${ }^{\mathrm{a}}$

\begin{tabular}{|c|c|c|c|c|c|c|c|c|c|c|c|c|c|c|c|}
\hline \multirow[b]{2}{*}{ Isolate } & \multicolumn{15}{|c|}{ Sporulation $\left(\times 10^{3}\right)$ on inoculated cucurbit host type ${ }^{b}$} \\
\hline & CS1 & $\mathrm{CS} 2$ & $\mathrm{CMr}$ & $\mathrm{CMc}$ & CP1 & $\mathrm{CP} 2$ & $\mathrm{CP} 3$ & CMo & $\mathrm{CMa}$ & $\mathrm{CL}$ & $\mathrm{BH}$ & LC & LS & $\mathrm{TC}$ & $\mathrm{MC}$ \\
\hline \multirow[t]{2}{*}{ 05A1 } & 16.5 & 16.6 & 5.2 & 7.3 & 0.0 & 0.2 & 0.5 & 2.9 & 18.6 & 1.3 & 0.0 & 0.0 & 19.9 & 5.0 & 0.0 \\
\hline & $(2.2)$ & $(16.2)$ & $(4.8)$ & $(3.9)$ & $(0.0)$ & $(0.2)$ & $(0.5)$ & $(2.9)$ & $(13.6)$ & $(1.3)$ & $(0.0)$ & $(0.0)$ & $(6.8)$ & $(5.0)$ & $(0.0)$ \\
\hline \multirow[t]{2}{*}{ 08A1 } & 14.5 & 13.7 & 6.0 & 3.1 & 0.6 & 0.0 & 0.3 & 0.0 & 4.1 & 0.0 & 1.2 & 0.0 & 13.1 & 0.5 & 0.0 \\
\hline & (1.7) & $(7.2)$ & (3.2) & $(0.1)$ & $(0.6)$ & $(0.0)$ & $(0.3)$ & $(0.0)$ & $(1.6)$ & $(0.0)$ & $(1.2)$ & $(0.0)$ & $(4.7)$ & $(0.1)$ & $(0.0)$ \\
\hline \multirow[t]{2}{*}{ 2013A18 } & 25.0 & 10.9 & 9.2 & 13.2 & 0.0 & 0.0 & 0.2 & 8.1 & 6.7 & 0.5 & 0.0 & 4.2 & 10.6 & 0.0 & 0.0 \\
\hline & $(19.0)$ & $(3.7)$ & $(1.1)$ & $(0.7)$ & $(0.0)$ & $(0.0)$ & $(0.2)$ & $(6.2)$ & $(2.0)$ & $(0.2)$ & $(0.0)$ & (3.3) & $(2.5)$ & $(0.0)$ & $(0.0)$ \\
\hline \multirow[t]{2}{*}{ 2013A19 } & 12.3 & 7.2 & 5.5 & 6.9 & 5.5 & 0.0 & 2.8 & 0.0 & 8.8 & 1.1 & 2.5 & 3.6 & 6.7 & 3.1 & 0.3 \\
\hline & (1.7) & $(5.6)$ & $(0.1)$ & $(4.7)$ & $(2.3)$ & $(0.0)$ & $(2.8)$ & $(0.0)$ & $(0.9)$ & $(1.1)$ & $(2.1)$ & $(2.3)$ & $(5.1)$ & $(1.2)$ & $(0.3)$ \\
\hline \multirow[t]{2}{*}{$2013 \mathrm{~A} 10$} & 7.8 & 1.4 & 15.9 & 0.0 & 0.0 & 0.0 & 2.9 & 0.0 & 1.7 & 0.0 & 1.2 & 1.7 & 0.0 & 3.6 & 0.0 \\
\hline & (1.9) & $(0.5)$ & (11.6) & $(0.0)$ & $(0.0)$ & $(0.0)$ & $(2.9)$ & $(0.0)$ & $(1.1)$ & $(0.0)$ & $(1.2)$ & (1.7) & $(0.0)$ & $(0.2)$ & $(0.0)$ \\
\hline \multirow[t]{2}{*}{ 2013A3 } & 24.7 & 3.3 & 7.1 & 7.0 & 0.0 & 0.0 & 0.0 & 11.5 & 9.2 & 0.0 & 0.0 & 0.0 & 0.6 & 0.0 & 0.0 \\
\hline & (15.9) & $(0.8)$ & $(7.1)$ & (3.9) & $(0.0)$ & $(0.0)$ & $(0.0)$ & $(9.7)$ & $(3.1)$ & $(0.0)$ & $(0.0)$ & $(0.0)$ & $(0.3)$ & $(0.0)$ & $(0.0)$ \\
\hline \multirow[t]{2}{*}{ A11 } & 10.9 & 13.3 & 11.5 & 7.9 & 1.6 & 0.0 & 0.0 & 0.0 & 21.7 & 0.4 & 7.0 & 0.0 & 24.3 & 3.1 & 0.6 \\
\hline & $(4.4)$ & $(1.4)$ & $(2.2)$ & (1.4) & $(1.6)$ & $(0.0)$ & $(0.0)$ & $(0.0)$ & $(1.7)$ & $(0.4)$ & $(2.0)$ & $(0.0)$ & (11.1) & $(3.1)$ & $(0.6)$ \\
\hline \multirow[t]{2}{*}{ 2013A15 } & 48.0 & 9.2 & 4.8 & 5.6 & 5.1 & 0.0 & 0.6 & 0.0 & 12.9 & 0.3 & 4.4 & 0.3 & 6.9 & 0.0 & 0.6 \\
\hline & $(28.4)$ & $(7.0)$ & $(3.6)$ & $(2.5)$ & $(5.1)$ & $(0.0)$ & $(0.3)$ & $(0.0)$ & $(2.9)$ & $(0.0)$ & $(2.8)$ & $(0.0)$ & $(5.0)$ & $(0.0)$ & $(0.6)$ \\
\hline \multirow[t]{2}{*}{ 2013A20 } & 20.4 & 9.1 & 2.5 & 1.6 & 0.0 & 0.3 & 10.5 & 17.8 & 29.4 & 3.3 & 6.6 & 0.3 & 5.3 & 6.1 & 0.5 \\
\hline & $(1.7)$ & $(0.6)$ & $(0.9)$ & $(0.0)$ & $(0.0)$ & $(0.3)$ & $(8.3)$ & (17.8) & (16.9) & $(2.0)$ & $(2.2)$ & $(0.3)$ & $(4.4)$ & $(5.4)$ & $(0.5)$ \\
\hline \multirow[t]{2}{*}{ 2013B17 } & 48.3 & 11.5 & 6.1 & 3.0 & 0.0 & 0.0 & 0.0 & 0.0 & 14.3 & 0.0 & 4.9 & 0.6 & 3.2 & 0.3 & 0.3 \\
\hline & (33.9) & $(7.5)$ & (3.9) & $(2.6)$ & $(0.0)$ & $(0.0)$ & $(0.0)$ & $(0.0)$ & $(5.6)$ & $(0.0)$ & $(0.9)$ & $(0.6)$ & $(3.2)$ & $(0.3)$ & $(0.3)$ \\
\hline \multirow[t]{2}{*}{$2013 C 3$} & 28.1 & 14.2 & 8.4 & 3.7 & 2.5 & 0.0 & 0.0 & 0.0 & 7.5 & 0.0 & 0.8 & 0.0 & 1.7 & 2.8 & 0.9 \\
\hline & $(9.4)$ & $(0.5)$ & $(3.4)$ & $(2.2)$ & (1.9) & $(0.0)$ & $(0.0)$ & $(0.0)$ & $(7.2)$ & $(0.0)$ & $(0.8)$ & $(0.0)$ & $(1.1)$ & $(2.8)$ & $(0.3)$ \\
\hline \multirow[t]{2}{*}{$08 \mathrm{C} 1$} & 46.7 & 4.5 & 6.7 & 9.0 & 1.7 & 0.6 & 4.4 & 0.4 & 12.9 & 0.3 & 5.0 & 4.2 & 4.8 & 5.6 & 1.6 \\
\hline & (15.4) & $(1.1)$ & $(0.1)$ & $(9.0)$ & (1.7) & $(0.6)$ & (3.7) & $(0.4)$ & $(4.8)$ & $(0.3)$ & $(2.8)$ & $(2.6)$ & $(6.4)$ & $(5.6)$ & $(0.3)$ \\
\hline \multirow[t]{2}{*}{ 2013E1 } & 7.3 & 0.0 & 23.0 & 5.1 & 1.7 & 1.1 & 9.7 & 3.0 & 17.7 & 8.4 & 0.6 & 3.7 & 3.2 & 2.8 & 0.0 \\
\hline & $(4.5)$ & $(0.0)$ & (15.2) & $(2.0)$ & (1.7) & $(0.5)$ & $(5.4)$ & $(3.0)$ & $(1.4)$ & $(2.8)$ & $(-)$ & $(0.9)$ & $(1.1)$ & $(2.5)$ & $(0.0)$ \\
\hline \multirow[t]{2}{*}{ 08E1 } & 7.8 & 0.6 & 3.6 & 4.1 & 15.5 & 5.0 & 6.5 & 1.2 & 6.1 & 17.1 & 14.1 & 0.0 & 9.6 & 1.9 & 0.0 \\
\hline & $(5.05)$ & $(0.6)$ & $(2.0)$ & $(0.6)$ & $(9.5)$ & $(2.5)$ & (1.5) & $(0.9)$ & $(2.3)$ & $(3.7)$ & $(11.2)$ & $(0.0)$ & $(4.3)$ & $(0.6)$ & $(0.0)$ \\
\hline \multirow[t]{2}{*}{ 08F1 } & 6.4 & 0.0 & 6.4 & 4.3 & 26.8 & 11.6 & 25.7 & 25.4 & 26.3 & 2.7 & 0.9 & 0.0 & 1.7 & 4.5 & 1.7 \\
\hline & $(6.4)$ & $(0.0)$ & (3.9) & $(1.2)$ & $(5.3)$ & $(2.3)$ & (18.9) & $(2.6)$ & (15.7) & $(1.1)$ & $(0.3)$ & $(0.0)$ & $(0.5)$ & $(0.5)$ & $(0.2)$ \\
\hline \multirow[t]{2}{*}{ D3 } & 32.9 & 16.4 & 5.6 & 4.2 & 23.6 & 46.2 & 12.8 & 39.5 & 27.6 & 4.1 & 2.6 & 0.3 & 1.2 & 2.0 & 0.0 \\
\hline & $(14.1)$ & (16.4) & $(3.1)$ & $(0.8)$ & (12.5) & (26.6) & $(3.1)$ & $(2.0)$ & $(6.7)$ & $(0.3)$ & $(2.6)$ & $(0.0)$ & $(0.6)$ & $(0.2)$ & $(0.0)$ \\
\hline 2013D4 & 5.4 & 0.0 & 10.1 & 3.9 & 34.8 & 19.3 & 24.8 & 31.7 & 33.7 & 4.1 & 4.8 & 3.4 & 2.5 & 3.7 & 2.0 \\
\hline & $(4.5)$ & $(0.0)$ & $(1.7)$ & $(1.4)$ & (11.4) & (11.2) & $(4.2)$ & $(1.1)$ & (13.1) & $(3.1)$ & $(4.8)$ & (2.5) & $(2.5)$ & (1.9) & (1.1) \\
\hline 2013D6 & 26.6 & 0.3 & 16.1 & 25.0 & 34.2 & 16.9 & 30.3 & 95.4 & 58.1 & 3.6 & 0.0 & 0.3 & 4.0 & 1.4 & 0.8 \\
\hline & (21.4) & $(0.3)$ & $(6.0)$ & $(15.0)$ & $(4.6)$ & $(4.4)$ & $(6.0)$ & (32.4) & $(7.5)$ & $(2.0)$ & $(0.0)$ & $(0.3)$ & $(2.7)$ & $(1.4)$ & $(0.8)$ \\
\hline $2013 \mathrm{~F} 2$ & 9.5 & 1.1 & 3.9 & 7.8 & 23.7 & 32.6 & 27.9 & 51.3 & 33.4 & 9.2 & 9.5 & 1.2 & 1.2 & 2.2 & 0.3 \\
\hline & $(3.3)$ & $(1.1)$ & $(2.0)$ & $(2.8)$ & $(8.1)$ & $(3.9)$ & $(9.8)$ & (15.8) & $(0.9)$ & $(7.3)$ & $(2.6)$ & $(0.3)$ & $(0.6)$ & $(0.9)$ & $(0.0)$ \\
\hline 2013F11 & 10.1 & 0.0 & 0.2 & 0.3 & 35.5 & 41.9 & 47.9 & 53.1 & 27.5 & 0.3 & 1.9 & 0.9 & 4.2 & 3.4 & 0.9 \\
\hline & (3.9) & $(0.0)$ & $(0.1)$ & $(0.3)$ & (12.7) & $(24.7)$ & $(2.9)$ & $(5.6)$ & (1.9) & $(0.0)$ & $(1.9)$ & $(0.9)$ & $(2.3)$ & $(1.2)$ & $(0.3)$ \\
\hline 2013D2 & 9.2 & 0.0 & 0.9 & 12.2 & 24.6 & 28.7 & 66.6 & 56.2 & 55.9 & 0.8 & 3.7 & 0.1 & 14.1 & 2.3 & 1.7 \\
\hline & $(7.3)$ & $(0.0)$ & $(0.6)$ & $(6.2)$ & $(1.8)$ & $(6.6)$ & (12.9) & $(25.0)$ & $(4.1)$ & $(0.5)$ & $(2.2)$ & $(0.1)$ & $(5.9)$ & $(0.5)$ & $(0.5)$ \\
\hline Pc1982 & 45.6 & 0.2 & 43.4 & 51.6 & 0.0 & 1.9 & 14.1 & 3.1 & 36.4 & 16.1 & 0.0 & 1.2 & 18.9 & 12.6 & 3.9 \\
\hline & $(2.5)$ & $(0.2)$ & $(6.6)$ & $(7.5)$ & $(0.0)$ & $(0.0)$ & $(5.0)$ & (1.2) & $(7.3)$ & $(5.5)$ & $(0.0)$ & (1.2) & $(4.8)$ & $(0.5)$ & $(0.2)$ \\
\hline
\end{tabular}

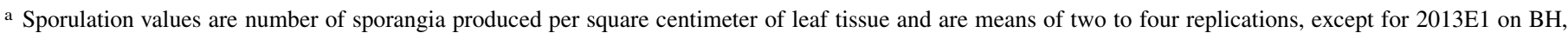
that was not replicated. Italicized values shown in parenthesis are standard errors of the mean for sporulation.

b Cucurbit host types are defined based on acronyms described in Table 2. 
were observed and all isolates evaluated were compatible with the susceptible cultivar of $C$. sativus, as reported in previous studies (Cohen et al. 2003; Lebeda and Gadasová 2002; Thomas et al. 1987). However, unlike the susceptible cultivar of $C$. sativus, approximately $50 \%$ of the isolates evaluated had either a very low compatibility or were incompatible with C. sativus 'Poinsett 76'. Poinsett 76 is a resistant cultivar developed from PI 197087 in the 1950s. It contains the $d m-1$ gene that had been effective until the resurgence of CDM in 2004 (Criswell et al. 2010; Cohen et al. 2015). Cucurbita maxima had the second highest number of compatible reactions, where all isolates except 2013A10 resulted in a compatible reaction. In the study by Thomas et al. (1987), isolates of $P$. cubensis that were incompatible with other Cucurbita spp. were also incompatible or lowly compatible with $C$. maxima. The observation by Thomas et al. (1987) is in contrast to results from the present study and studies conducted in the Czech Republic (Lebeda and Gadasová 2002) and Malaysia (Salati et al. 2010), where most of the isolates that were incompatible with other Cucurbita spp. were highly compatible with $C$. maxima. Differences in the pathogenic profile of isolates and host genetic makeup may explain the high compatibility with $C$. maxima observed in the present study, unlike in the study by Thomas et al. (1987). Similar to other studies conducted in Israel (Lebeda and Cohen 2011) and the Czech Republic (Lebeda and Widrlechner 2003; Lebeda et al. 2013), Luffa cylindrica and $M$. charantia exhibited the lowest level of

TABLE 4. Summary of analysis of sporulation intensity and disease severity on inoculated host differentials to determine compatibility of Pseudoperonospora cubensis with cucurbit host types

\begin{tabular}{|c|c|c|c|c|c|c|}
\hline \multirow[b]{2}{*}{ Source } & \multirow[b]{2}{*}{$\mathrm{ndf}^{\mathrm{a}}$} & \multirow[b]{2}{*}{$\mathrm{ddf}^{\mathrm{a}}$} & \multicolumn{2}{|c|}{ Sporulation } & \multicolumn{2}{|c|}{$\begin{array}{l}\text { Disease } \\
\text { severity }\end{array}$} \\
\hline & & & $F$ & $\operatorname{Pr}>F$ & $F$ & $\operatorname{Pr}>F$ \\
\hline Isolate & 21 & 325 & 10.37 & 0.0001 & 7.22 & 0.0001 \\
\hline Differential & 14 & 325 & 25.39 & 0.0001 & 30.65 & 0.0001 \\
\hline Isolate $\times$ differential & 280 & 325 & 3.17 & 0.0001 & 2.57 & 0.0001 \\
\hline
\end{tabular}

a Abbreviations: ndf $=$ numerator degrees of freedom and $\mathrm{ddf}=$ denominator degrees of freedom. compatibility with our test isolates. However, L. cylindrica and other Luffa spp. have been reported to be highly compatible with P. cubensis isolates in China (Cohen et al. 2015) and India (Jamadar and Desai 1999). Thus, the P. cubensis populations in the United States or Czech Republic may be composed of a pathotype that is distinctively different from that in the pathogen populations in India or China.

As is the case for many other oomycete plant pathogens, description of pathotypes provides a useful means to characterize and, thereby, understand the virulence structure of $P$. cubensis within a given population (McDonald and Linde 2002). Following the 2004 resurgence of CDM in the United States, Colucci (2008) observed a broader virulence pattern of $P$. cubensis than previously reported by Thomas et al. (1987) but did not describe the pathotypes or their distribution. In the present study, five pathotypes were described from a total of 22 isolates evaluated. Three of these pathotypes - pathotype 1, which includes 1(A); pathotype 3, which includes 3(B) and 3(C); and pathotype 6, which includes 6(A) - had previously not been reported in the United States. Pathotype 6 was reported for the first time following the resurgence of CDM in Israel in 2002 (Cohen et al. 2003). Pathotypes 1 and 3, which were previously reported to be present only in East Asia and Israel (Cohen et al. 2003; Thomas et al. 1987), were also the most predominant in the present study. Pathotype 4 and 5 isolates were previously present in the United States, with all Cucurbita spp. being compatible with pathotype 5 but not with pathotype 4 isolates (Thomas et al. 1987). However, although pathotype 4 isolates in the present study were not compatible with C. pepo subsp. ovifera, they were compatible with $C$. pepo subsp. pepo. This suggests that a specific interaction between $P$. cubensis and Cucurbita spp. exists at the host subspecies level that may need to be considered in selecting host types to include in a differential set when determining pathotypes of $P$. cubensis. This partly supports an earlier hypothesis by Lebeda et al. (2006) on the existence of P. cubensis races on various genera and species of cucurbits and the importance of their specification. This assumption was recently confirmed by detailed studies on virulence variability of $P$. cubensis on Cucumis melo (Lebeda et al. 2016b) and Cucurbita spp. (Lebeda et al. 2016a).

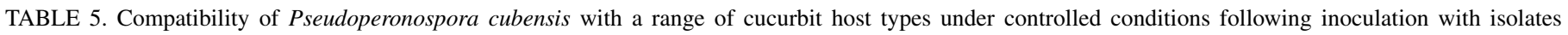
collected from different cucurbits across the United States

\begin{tabular}{|c|c|c|c|c|c|c|c|c|c|c|c|c|c|c|c|}
\hline \multirow[b]{2}{*}{ Isolate } & \multicolumn{15}{|c|}{ Cucurbit host type ${ }^{a}$} \\
\hline & $\mathrm{CS} 1$ & $\mathrm{CS} 2$ & $\mathrm{CMr}$ & $\mathrm{CMc}$ & $\mathrm{CP} 1$ & $\mathrm{CP} 2$ & CP3 & CMo & $\mathrm{CMa}$ & CL & $\mathrm{BH}$ & $\mathrm{LC}$ & LS & $\mathrm{TC}$ & $\mathrm{MC}$ \\
\hline 05A1 & +++ & +++ & +++ & +++ & - & \pm & - & \pm & +++ & \pm & - & - & +++ & \pm & - \\
\hline 08A1 & +++ & +++ & +++ & ++ & - & - & - & - & +++ & - & \pm & - & +++ & - & - \\
\hline 2013A18 & +++ & +++ & +++ & +++ & - & - & \pm & \pm & +++ & \pm & - & \pm & +++ & - & - \\
\hline 2013A19 & +++ & +++ & +++ & +++ & - & - & \pm & - & +++ & \pm & - & \pm & +++ & - & - \\
\hline 2013A10 & +++ & \pm & +++ & - & - & - & \pm & - & \pm & - & \pm & \pm & \pm & - & - \\
\hline 2013A3 & +++ & \pm & +++ & + & - & - & - & \pm & +++ & - & - & - & \pm & - & - \\
\hline A11 & +++ & +++ & +++ & +++ & - & - & - & - & +++ & - & +++ & - & +++ & + & - \\
\hline 2013A15 & +++ & +++ & +++ & +++ & +++ & - & \pm & \pm & +++ & - & ++ & - & +++ & - & - \\
\hline 2013A20 & +++ & +++ & + & \pm & - & \pm & \pm & ++ & +++ & ++ & +++ & - & +++ & +++ & \pm \\
\hline 2013B17 & +++ & +++ & +++ & ++ & \pm & - & - & \pm & +++ & - & + & - & ++ & - & - \\
\hline $2013 C 3$ & +++ & +++ & +++ & ++ & + & - & - & - & +++ & - & - & - & + & + & \pm \\
\hline $08 \mathrm{C} 1$ & +++ & +++ & +++ & ++ & \pm & - & + & - & +++ & - & ++ & \pm & ++ & \pm & \pm \\
\hline 2013E1 & +++ & \pm & +++ & +++ & \pm & \pm & +++ & \pm & +++ & +++ & - & \pm & + & + & \pm \\
\hline 08E1 & +++ & \pm & ++ & \pm & ++ & ++ & +++ & \pm & +++ & +++ & +++ & - & +++ & \pm & - \\
\hline 08F1 & +++ & - & +++ & + & +++ & +++ & +++ & +++ & +++ & + & \pm & - & - & ++ & - \\
\hline D3 & +++ & + & +++ & +++ & +++ & +++ & +++ & +++ & +++ & ++ & \pm & - & \pm & \pm & \pm \\
\hline 2013D4 & +++ & - & +++ & +++ & +++ & +++ & +++ & +++ & +++ & +++ & ++ & \pm & + & + & \pm \\
\hline 2013D6 & +++ & - & +++ & +++ & +++ & +++ & +++ & +++ & +++ & ++ & - & \pm & ++ & \pm & - \\
\hline $2013 F 2$ & +++ & \pm & +++ & +++ & +++ & +++ & +++ & +++ & +++ & +++ & +++ & \pm & \pm & \pm & - \\
\hline 2013F11 & +++ & - & \pm & \pm & +++ & +++ & +++ & +++ & +++ & \pm & \pm & \pm & ++ & ++ & \pm \\
\hline 2013D2 & +++ & - & + & +++ & +++ & +++ & +++ & +++ & +++ & \pm & \pm & - & +++ & + & \pm \\
\hline Pc1982 & +++ & - & +++ & +++ & - & \pm & +++ & \pm & +++ & +++ & - & \pm & +++ & +++ & + \\
\hline
\end{tabular}

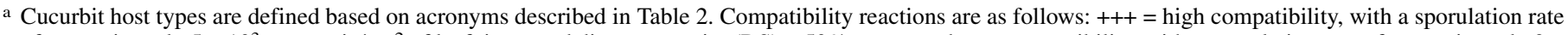
of approximately $5 \times 10^{3}$ sporangia/ $\mathrm{cm}^{2}$ of leaf tissue and disease severity (DS) $\geq 50 \% ;++=$ moderate compatibility, with a sporulation rate of approximately $3 \times$ $10^{3}$ sporangia/ $\mathrm{cm}^{2}$ leaf tissue and $20 \% \leq \mathrm{DS}<50 \% ;+=$ low compatibility, with a sporulation rate of approximately $2 \times 10^{3}$ sporangia/cm ${ }^{2}$ leaf tissue and $5 \%<$ DS $<20 \% ; \pm=$ very low compatibility, with sparse sporulation; and $-=$ incompatible, with no evidence of sporulation or disease symptoms. 
A distinct pattern in the distribution of pathotypes across the United States was evident in this study. Most of the isolates collected from the northern states (Michigan, New Jersey, New York, and Ohio) were either pathotype 1 or pathotype 3, whereas isolates collected from the southern states (Alabama, Florida, Georgia, North Carolina, South Carolina, and Texas) were diverse and belonged to all five pathotypes reported in this study. The diversity of pathotypes in southern states could be due to the proximity of these states to the overwintering sources in southern Florida and along the edge of the Gulf of Mexico, where a diverse range of cucurbits are cultivated year round. Overwintering hosts and seasonally cultivated cucurbit species exert different degrees of

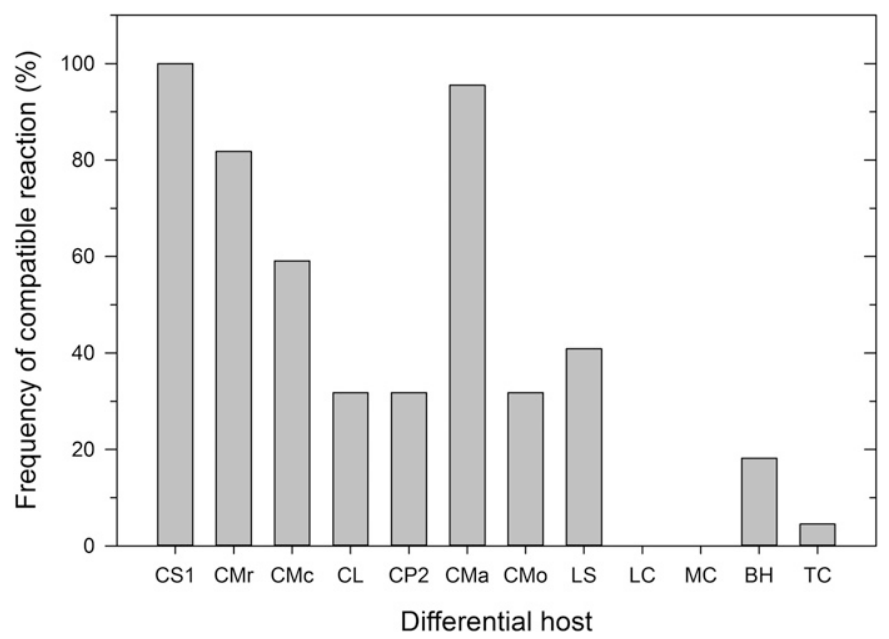

Fig. 1. Variation in the susceptibility of cucurbit host types used as differentials to establish the virulence structure of Pseudoperonospora cubensis in the United States. Each bar represents the proportion of isolates with a compatible reaction relative to the total number of isolates examined. selection pressure that result in differences in prevailing pathotypes in specific geographic areas (Thomas et al. 1987). A high genetic diversity has also been detected in $P$. cubensis populations in the southern states of Georgia and North Carolina (Quesada-Ocampo et al. 2012). A closer examination of the compatibility reactions shows that isolates belonging to pathotypes 1 and 3 were compatible with $C$. sativus Poinsett 76, whereas isolates belonging to all other pathotypes exhibited either an incompatible or a very lowly compatible reaction with Poinsett 76 . Given that Poinsett 76 was a highly resistant cultivar (Criswell et al. 2010) and pathotypes 1 and 3 had not been reported in the United States prior to 2004, the breakdown of resistance in Poinsett 76 and other resistant cucumber cultivars that resulted in the resurgence of CDM in the United States may have been due to the introduction of an aggressive strain of pathotype 1 or 3 .

Pathotypes of $P$. cubensis in the United States have not been characterized following the initial study by Thomas et al. (1987). Thus, the host differential set developed by Thomas et al. (1987) serves a useful baseline for establishing whether new pathotypes are present in the current population of $P$. cubensis in the United States. Unavailability of some differentials (e.g., C. melo var. acidulous) used earlier (Thomas et al. 1987) led to some isolates not grouping perfectly within pathotypes described by Thomas et al. (1987). For example, isolate 2013A3 was compatible with $C$. sativus and $C$. melo var. reticulatus and would be designated as pathotype 1 based on Thomas et al. (1987). However, 2013A3 was compatible with C. maxima, unlike in the study by Thomas et al. (1987), where pathotype 1 isolates were only lowly incompatible with $C$. maxima. The high sporulation cutoff value used by Thomas et al. (1987) may partly explain differences observed between the two studies. Compatibility of $C$. maxima with several $P$. cubensis isolates based on the sporulation cutoff used in the present study has also been reported elsewhere (Lebeda and Gadasová 2002; Lebeda and Widrlechner 2003; Lebeda et al. 2013). Thus, rather than assign 2013A3 a new pathotype, that isolate was designated as pathotype

TABLE 6. Pathotype designation, virulence characteristics, and mating type of Pseudoperonospora cubensis isolates collected from different cucurbits across the United States

\begin{tabular}{|c|c|c|c|c|c|c|c|c|c|c|c|c|c|c|c|c|}
\hline \multirow[b]{2}{*}{ Isolate } & \multicolumn{12}{|c|}{ Host differential $^{\mathrm{a}}$} & \multirow[b]{2}{*}{$\mathrm{PP}^{\mathrm{b}}$} & \multirow[b]{2}{*}{$V f^{c}$} & \multirow[b]{2}{*}{$\mathrm{Vp}^{\mathrm{d}}$} & \multirow[b]{2}{*}{$\mathrm{MT}^{\mathrm{e}}$} \\
\hline & CS1 & $\mathrm{CMr}$ & $\mathrm{CMc}$ & $\mathrm{CL}$ & $\mathrm{CP} 2$ & $\mathrm{CMa}$ & CMo & LS & $\mathrm{LC}$ & $\mathrm{MC}$ & $\mathrm{BH}$ & $\mathrm{TC}$ & & & & \\
\hline 2013A10 & + & + & - & - & - & - & - & - & - & - & - & - & 1 & 2 & $\mathrm{P} 1$ & A1 \\
\hline $2013 \mathrm{~A} 3$ & + & + & - & - & - & + & - & - & - & - & - & - & $1(\mathrm{~A})$ & 3 & $\mathrm{P} 2$ & A1 \\
\hline 2013B17 & + & + & - & - & - & + & - & - & - & - & - & - & $1(\mathrm{~A})$ & 3 & $\mathrm{P} 2$ & A1 \\
\hline $2013 C 3$ & + & + & - & - & - & + & - & - & - & - & - & - & $1(\mathrm{~A})$ & 3 & $\mathrm{P} 2$ & A1 \\
\hline $08 \mathrm{C} 1$ & + & + & - & - & - & + & - & - & - & - & - & - & 1 (A) & 3 & $\mathrm{P} 2$ & A1 \\
\hline 05A1 & + & + & + & - & - & + & - & + & - & - & - & - & 3 (A) & 5 & P3 & A1 \\
\hline 08A1 & + & + & + & - & - & + & - & + & - & - & - & - & 3 (A) & 5 & P3 & A1 \\
\hline 2013A18 & + & + & + & - & - & + & - & + & - & - & - & - & 3 (A) & 5 & P3 & A1 \\
\hline 2013A19 & + & + & + & - & - & + & - & + & - & - & - & - & $3(\mathrm{~A})$ & 5 & P3 & A1 \\
\hline $2013 \mathrm{~A} 15$ & + & + & + & - & - & + & - & + & - & - & - & - & 3 (A) & 5 & P3 & A1 \\
\hline A11 & + & + & + & - & - & + & - & + & - & - & + & - & 3 (B) & 6 & $\mathrm{P} 4$ & A1 \\
\hline 2013A20 & + & - & - & - & - & + & - & + & - & - & + & + & $3(\mathrm{C})$ & 5 & P5 & A1 \\
\hline Pc1982 & + & + & + & + & - & + & - & + & - & - & - & + & 4 & 7 & P6 & A2 \\
\hline 2013E1 & + & + & + & + & - & + & - & - & - & - & - & - & 4 & 5 & P7 & A2 \\
\hline $08 \mathrm{E} 1$ & + & - & - & + & - & + & - & + & - & - & + & - & $4(\mathrm{~A})$ & 5 & P8 & A2 \\
\hline D3 & + & + & + & + & + & + & + & - & - & - & - & - & 5 & 7 & P9 & A2 \\
\hline 2013D4 & + & + & + & + & + & + & + & - & - & - & - & - & 5 & 7 & P9 & A2 \\
\hline 2013D6 & + & + & + & + & + & + & + & - & - & - & - & - & 5 & 7 & P9 & A2 \\
\hline $2013 F 2$ & + & + & + & + & + & + & + & - & - & - & + & - & $5(\mathrm{~A})$ & 8 & P10 & A2 \\
\hline 2013D2 & + & - & + & - & + & + & + & + & - & - & - & - & 6 & 6 & P11 & A2 \\
\hline 08F1 & + & + & - & - & + & + & + & - & - & - & - & - & $6(\mathrm{~A})$ & 5 & $\mathrm{P} 12$ & A2 \\
\hline 2013F11 & + & - & - & - & + & + & + & - & - & - & - & - & $6(\mathrm{~B})$ & 4 & $\mathrm{P} 13$ & A2 \\
\hline
\end{tabular}

a Cucurbit host differentials are defined based on acronyms described in Table 2.

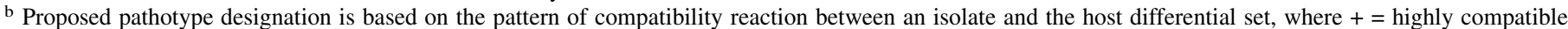
reaction and $-=$ moderate, low, and very low compatibility or incompatible reaction based on the compatibility scheme originally developed by Thomas et al. (1987) and later expanded by Lebeda and Widrlechner (2003) and Cohen et al. (2015). Letters in parenthesis refer to a variant of a pathotype that largely conforms to the Thomas et al. (1987) model but differs in one or two compatibility reactions.

c Virulence factor of an isolate based on the number of compatible reactions with the host differential set.

${ }^{\mathrm{d}}$ Virulence phenotype of an isolate based on a unique pattern of compatible or incompatible (i.e., + or - ) reactions with the differentials.

e Mating type. 
1A (i.e., a variant of pathotype 1 that is compatible with $C$. maxima). This approach was adopted to assign pathotypes to isolates that did not perfectly fit the Thomas et al. (1987) model. Studies conducted on $P$. cubensis populations in the Czech Republic (Lebeda and Gadasová 2002) and Malaysia (Salati et al. 2010) have also reported a lack of perfect fit with the pathotype model proposed by Thomas et al. (1987). Based on the differential set used in the present study, Lebeda and Gadasová (2002) observed that only 1 of their 22 isolates tested corresponded to the pathotype model of Thomas et al. (1987). This was attributed to the limited taxonomic range of the differential set used by Thomas et al. (1987), making it unable to capture the extent of virulence variability within P. cubensis (Lebeda and Widrlechner 2003). Nonetheless, the pathotypes described in the present study serve as a useful working framework for subsequent studies on the structure and variability of virulence of $P$. cubensis in the United States.

The level of virulence of all isolates examined in this study was moderate, with a mean $v$-factor of 5.1 across the entire population. Although virulence of $P$. cubensis isolates in the United States has previously been examined (Colucci 2008), the level of virulence was not quantified in that study and, thus, we are unable to compare our findings with those reported by Colucci (2008). Additionally, the level of virulence observed in the present study is comparatively lower than that reported for $P$. cubensis in the Czech Republic, where the pathogen population has been reported to have a high level of virulence, with a mean v-factor of 9.0 (Lebeda et al. 2013). In the present study, v-phenotypes, complexity, and diversity were
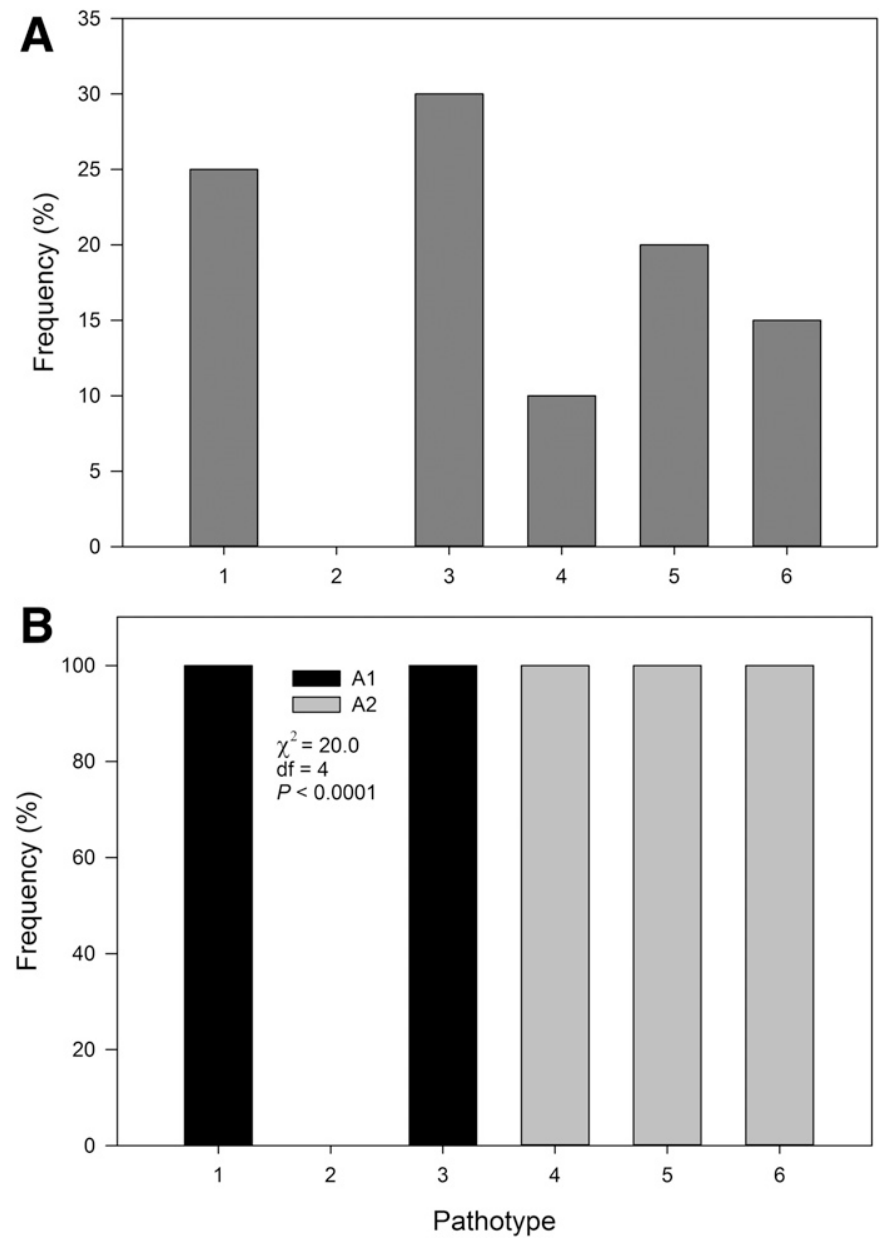

Fig. 2. Frequency distribution of pathotypes of Pseudoperonospora cubensis based on isolates collected from various cucurbit host types in the United States. A, Frequency distribution of all $P$. cubensis isolates within each pathotype and $\mathbf{B}$, frequency distribution of isolates of the A1 and A2 mating type within each pathotype of $P$. cubensis. analyzed to determine differences in the $P$. cubensis population in the United States. Thirteen v-phenotypes were identified and it is likely that v-phenotypes P6, P7, P8, P9, and P10 were present in the United States prior to 2004 because they were identified as pathotypes 4 and 5 described earlier by Thomas et al. (1987). All the other v-phenotypes were not associated with previously described pathotypes and could be considered new v-phenotypes. In addition, V-phenotypes P1 and P2 (pathotype 1) and P3, P4, and P5 (pathotype 3 ) were compatible with Poinsett 76 and they may be associated with the resurgence of CDM in 2004. Diversity estimates indicated that virulence diversity within the $P$. cubensis population in the United States is high. Although virulence diversity estimates for $P$. cubensis have not been reported prior to this study, the normalized estimate for Shannon index of diversity reported here is comparable to that of Phytophthora infestans $\left(H_{\mathrm{SR}}=0.72\right)$ infecting potato and tomato in the United States (Andrivon 1994). This high virulence diversity is consistent with the high virulence variability observed in this study. High virulence variation of Pseudoperonospora cubensis has also been reported in the Czech Republic (Lebeda et al. 2013). Although specific estimates of virulence diversity were not presented in the study by Lebeda et al. (2013), 67 pathotypes were determined from a total of 389 isolates of $P$. cubensis. Further, the mean virulence complexity $\left(C_{\mathrm{i}}=5.05\right.$ and $\left.C_{\mathrm{p}}=5.23\right)$ observed in the present study was high, with $\mathrm{v}$-factors per isolate and $\mathrm{v}$-factors per v-phenotype equally contributing to virulence complexity of $P$. cubensis. The high virulence variability observed in this study verifies the genetic flexibility of $P$. cubensis and its ability to evolve and adapt more rapidly to fungicides and changes in cucurbit hosts (Quesada-Ocampo et al. 2012).

The pathotypes of isolates evaluated in this study were significantly associated with the mating type of the corresponding isolates. Specifically, all pathotype 1 and 3 isolates were of the A1 mating type, whereas pathotype 4, 5, and 6 isolates were of the A2 mating type. Molecular studies conducted on P. cubensis in the Czech Republic showed that isolates sampled before the shift in virulence in 2009 exhibited the genotype of the subspecies of clade II, whereas isolates sampled after the shift in virulence exhibited a genotype of the subspecies of clade I (Kitner et al. 2015). It was suggested that genotypes within clade II, probably indigenous to East Asia, were of the A1 mating type, whereas genotypes in clade I were the A2 mating type of P. cubensis (Lebeda et al. 2014). Isolates belonging to pathotypes 1 and 3 were also of the A1 mating type and had not been previously reported in the United States. Given that pathotype 1 and 3 isolates were indigenous to East Asia, it is highly possible that they were introduced from East Asia to the United States via Europe (Runge et al. 2011) through anthropogenic activities. In addition, because only isolates of pathotypes 1 and 3 were compatible with Poinsett 76, which was resistant to CDM until 2004, the findings in Kitner et al. (2015) provide additional support that pathotype 1 and 3 isolates may have been responsible for the resurgence of CDM in the United States in 2004. New pathotypes of $P$. cubensis that are aggressive and cause severe epidemics on Cucurbita spp. and Citrullus lanatus have also been reported since 2009 in the Czech Republic (Kitner et al. 2015; Lebeda et al. 2012, 2014). These new pathotypes have been linked with an increase in virulence within the pathogen population in the Czech Republic, and most of the isolates belonging to these new pathotypes also contain signatures of sexual recombination (Kitner et al. 2015). Although genetic signatures of pathotype 1 and 3 isolates (A1 isolates) reported in this study were not examined, it is also possible that a recombinant $\mathrm{F} 1$ heterozygote of the A1 mating type that was fit and able to survive and rapidly spread across the eastern states may have been responsible for the resurgence of CDM in the United States.

The high pathogenic variability observed in this study indicates that $P$. cubensis has the genetic plasticity to evolve rapidly. Recently, the pathogen has also been shown to have the ability to reproduce sexually in the United States (Thomas et al. 2017). The latter characteristic is expected to facilitate the rapid evolution (McDonald and Linde 2002) of $P$. cubensis, leading to a high risk for 
developing resistance to available fungicides and less durability of resistance in new cultivars that may be deployed for controlling CDM. Indeed, reduced efficacy for specific fungicides used to control CDM in the United States has been reported (Adams and Quesada-Ocampo 2014; Ojiambo et al. 2010). Thus, it is unlikely that resistance alone in cucurbit cultivars will be effective to control CDM. An integrated approach involving a combination of timely application of fungicides, rotation of fungicides with different chemistries, and introduction of cultivars with new resistance genes will be required for effective disease management.

\section{ACKNOWLEDGMENTS}

This study was supported by Hatch Funds from North Carolina Agricultural Experiment Station for Project Number NC02251 and NC02432. A. Lebeda's work was supported by project MSM 6198959215 (Ministry of Education, Youth and Sports) and project QH 71254 (Czech Ministry of Agriculture).We thank collaborators on the CDM ipmPIPE project for their assistance in collecting field samples used in this study, and T. Ghiloni and B. Stevens for assistance with laboratory and greenhouse aspects of this work.

\section{LITERATURE CITED}

Adams, M. L., and Quesada-Ocampo, L. M. 2014. Evaluation of fungicides for control of downy mildew on cucumber. Kinston 2013. Plant Dis. Manage. Rep. 8:V240.

Andrivon, D. 1994. Race structure and dynamics in populations of Phytophthora infestans. Can. J. Bot. 72:1681-1687.

Anonymous. 2016. Vegetables 2015 Summary. Online publication. United States Department of Agriculture-National Agricultural Statistics Service. http://usda.mannlib.cornell.edu/usda/nass/VegeSumm//2010s/2016/VegeSumm02-04-2016.pdf

Barnes, W. C., and Epps, W. M. 1954. An unreported type of resistance to cucumber downy mildew. Plant Dis. Rep. 38:620.

Cappelli, C., Buonaurio, R., and Stravato, V. M. 2003. Occurrence of Pseudoperonospora cubensis pathotype 5 on squash in Italy. Plant Dis. 87:449.

Cespedes-Sanchez, M. C., Naegele, R. P., Kousik, C. S., and Hausbeck, M. K. 2015. Field response of cucurbit hosts to Pseudoperonospora cubensis in Michigan. Plant Dis. 99:676-682.

Cohen, Y., Meron, I., Mor, N., and Zuriel, S. 2003. A new pathotype of Pseudoperonospora cubensis causing downy mildew in cucurbits in Israel. Phytoparasitica 31:458-466.

Cohen, Y., and Rubin, A. E. 2012. Mating type and sexual reproduction of Pseudoperonospora cubensis, the downy mildew agent of cucurbits. Eur. J. Plant Pathol. 132:577-592.

Cohen, Y., Van den Langenberg, K. M., Wehner, T. C., Ojiambo, P. S., Hausbeck, M., Quesada-Ocampo, L. M., Lebeda, A., Sierotzki, H., and Gisi, U. 2015. Resurgence of Pseudoperonospora cubensis-The agent of cucurbit downy mildew. Phytopathology 105:998-1012.

Colucci, S. J. 2008. Host range, fungicide resistance and management of Pseudoperonospora cubensis, causal agent of cucurbit downy mildew. MS thesis, North Carolina State University. https://repository.lib.ncsu.edu/handle/ $1840.16 / 2795$

Criswell, A. D., Call, A. D., and Wehner, T. C. 2010. Genetic control of downy mildew resistance in cucumber-A review. Cucurbit Genet. Coop. Rep. 33-34: 13-16.

Holmes, G. J., Ojiambo, P. S., Hausbeck, M. K., Quesada-Ocampo, L., and Keinath, A. P. 2015. Resurgence of cucurbit downy mildew in the United States: A watershed event for research and extension. Plant Dis. 99:428-441.

Holmes, G. J., Wehner, T., and Thornton, A. 2006. An old enemy re-emerges. Am. Veg. Grow. 54:14-15.

Jamadar, M. M., and Desai, S. A. 1999. Reaction of ridgegourd local cultivars against downy mildew caused by Pseudoperonospora cubensis (Berk. et Curt.) Rostow. Karnataka J. Agric. Sci. 12:204-205.

Kitner, M., Lebeda, A., Sharma, R., Runge, F., Dvořák, P., Tahir, A., Choi, Y.-J., Sedláková, B., and Thines, M. 2015. Coincidence of virulence shifts and population genetic changes of Pseudoperonospora cubensis in the Czech Republic. Plant Pathol. 64:1461-1470.

Lebeda, A. 1982. Measurement of genetic diversity of virulence in populations of phytopathogenic fungi. J. Plant Dis. Prot. 89:88-95.

Lebeda, A. 1992. Screening of wild Cucumis sp. against downy mildew (Pseudoperonospora cubensis) isolates from cucumbers. Phytoparasitica 20:203-210
Lebeda, A., and Cohen, Y. 2011. Cucurbit downy mildew (Pseudoperonospora cubensis)—Biology, ecology, epidemiology, host-pathogen interaction and control. Eur. J. Plant Pathol. 129:157-192.

Lebeda, A., and Gadasová, V. 2002. Pathogenic variation of Pseudoperonospora cubensis in the Czech Republic and some other European countries. Acta Hortic. 588:137-141.

Lebeda, A., Kitner, M., Sedlakova, B., Sharma, R., Runge, F., and Thines, M. 2014. Biological and molecular evidences about changes in the host range and virulence of Pseudoperonospora cubensis populations in the Czech Republic. Pages 24-27 in: Proc. Cucurbitaceae 2014. M. Havey, Y. Weng, B. Day, and R. Grumet, eds. Michigan State University and University of WisconsinMadison, American Society for Horticultural Science, Alexandria, VA.

Lebeda, A., Kř́stková, E., Roháčková, J., Sedláková, B., Widrlechner, M. P., and Paris, H. S. 2016a. Race-specific resistance of Cucurbita germplasm to Pseudoperonospora cubensis. Euphytica 212:145-156.

Lebeda, A., Křístková, E., Štěpánková, J., Sedláková, B., and Widrlechner, M. P. 2016b. Response of Cucumis melo accessions to isolates of Pseudoperonospora cubensis with different levels of virulence. Sci. Hortic. (Amsterdam) 200:45-54.

Lebeda, A., Pavelková, J., Sedláková, B., and Urban, J. 2013. Structure and temporal shifts in virulence of Pseudoperonospora cubensis populations in the Czech Republic. Plant Pathol. 62:336-345.

Lebeda, A., Pavelkova, J., Urban, J., and Sedlakova, B. 2011. Distribution, host range and disease severity of Pseudoperonospora cubensis on cucurbits in the Czech Republic. J. Phytopathol. 159:589-596.

Lebeda, A., and Sedláková, B., and Pavelková, J. 2012. New hosts of Pseudoperonospora cubensis in the Czech Republic and pathogen virulence variation. Pages 768-776 in: Cucurbitaceae 2012. Proc. Xth EUCARPIA Meet. Genet. Breed. Cucurbitaceae. N. Sari, I. Solmaz, and V. Aras, eds. Antalya, Turkey.

Lebeda, A., and Widrlechner, M. P. 2003. A set of cucurbitaceae taxa for differentiation of Pseudoperonospora cubensis pathotypes. J. Plant Dis. Prot. 110:337-349.

Lebeda, A., Widrlechner, M. P., Staub, J., Ezura, H., Zalapa, J., and Kř́stková, E. 2007. Cucurbits (Cucurbitaceae; Cucumis spp., Cucurbita spp., Citrullus spp.). Pages 277-377 in: Genetic Resources, Chromosome Engineering and Crop Improvement, Vol. 3. Vegetable Crops. R. Singh, ed. CRC Press, Boca Raton, FL.

Lebeda, A., Widrlechner, M. P., and Urban, J. 2006. Individual and population aspects of interactions between cucurbits and Pseudoperonospora cubensis: Pathotypes and races. Pages 453-467 in: Proc. Cucurbitaceae 2006. G. J. Holmes, ed. Universal Press, Raleigh, NC.

McDonald, B., and Linde, C. 2002. Pathogen population genetics, evolutionary potential, and durable resistance. Annu. Rev. Phytopathol. 40:349-379.

Ojiambo, P. S., Gent, D. H., Quesada-Ocampo, L. M., Hausbeck, M. K., and Holmes, G. J. 2015. Epidemiology and population biology of Pseudoperonospora cubensis: A model system for management of downy mildews. Annu. Rev. Phytopathol. 53:223-246.

Ojiambo, P. S., Holmes, G. J., Britton, W., Keever, T., Adams, M. L., Babadoost, M., Bost, S. C., Boyles, R., Brooks, M., Damicone, J., Draper, M. A., Egel, D. S., Everts, K. L., Ferrin, D. M., Gevens, A. J., Gugino, B. K., Hausbeck, M. K., Ingram, D. M., Isakeit, T., Keniath, A. P., Koike, S. T., Langston, D., McGrath, M. T., Miller, S. A., Mulrooney, R., Rideout, S., Roddy, E., Seebold, K. W., Sikora, E. J., Thornton, A., Wick, R. L., Wyenandt, A. A., and Zhanga, S. 2011. Cucurbit downy mildew ipmPIPE: A next generation web-based interactive tool for disease management and extension outreach. Online publication. Plant Health Prog. doi:10.1094/ PHP-2011-0411-01-RV

Ojiambo, P. S., Paul, P. A., and Holmes, G. J. 2010. A quantitative review of fungicide efficacy for managing downy mildew in cucurbits. Phytopathology 100:1066-1076.

Quesada-Ocampo, L. M., Granke, L. L., Olsen, J., Gutting, H. C., Runge, F., Thines, M., Lebeda, A., and Hauesbeck, M. K. 2012. The genetic structure of Pseudoperonospora cubensis populations. Plant Dis. 96:1459-1470.

Runge, F., Choi, Y., and Thines, M. 2011. Phylogenetic investigations in the genus Pseudoperonospora reveal overlooked species and cryptic diversity in the P. cubensis species cluster. Eur. J. Plant Pathol. 129:135-146.

Salati, M., Fun, W., Meon, S., and Masdek, H. N. 2010. Host range evaluation and morphological characterization of Pseudoperonospora cubensis, the causal agent of cucurbit downy mildew in Malaysia. Afr. J. Biotechnol. 9: 4897-4903.

Thomas, A., Carbone, I., Cohen, Y., and Ojiambo, P. S. 2017. Occurrence and distribution of mating types of Pseudoperonospora cubensis in the United States. Phytopathology 107:313-321.

Thomas, C., Inaba, T., and Cohen, Y. 1987. Physiological specialization in Pseudoperonospora cubensis. Phytopathology 77:1621-1624. 